\title{
Hitachi opens new labs
}

\section{Tokyo}

HrTACHI Ltd of Japan last week announced the opening of four research laboratories in the United States and Europe that will form close ties with nearby universities. Hitachi's move is the latest in a series of steps by Japan's industrial giants to form links with universities in the West, and it has raised fears that Japan is trying to tap the brains of Western academic institutions. But university researchers involved in the collaboration see the joint research as mutually beneficial.

Hitachi's new laboratories, which will open within the next few months, will be in the Cavendish Laboratory of the University of Cambridge in the United Kingdom, the O'Reilly Institute of Trinity College at the University of Dublin in Ireland, and within Hitachi America Ltd at San Francisco and Detroit in the United States. The arrangement with the University of Cambridge is particularly novel.

The Cavendish Laboratory, one of the world's leading research institutes with a string of Nobel prizewinners to its name, has been desperately seeking funds for a new building for its microelectronic researchers who are currently housed on a separate site at the Science Park in Cambridge. The lease on their building in the park runs out in September and cannot be renewed, according to Dr $\mathrm{H}$. Ahmed, head of the microelectronics laboratory.

Unable to get support from the government, the university has had to dig into its trust funds and turn to Hitachi and another Japanese company for help. Hitachi has donated $£ 250,000$, or nearly a third of the $£ 800,000$ needed for construction of the building, and Japan's Toshiba Corporation has also given $£ 50,000$, says John Deakin, secretary of the Cavendish Laboratory. Construction is expected to be completed in December.

Toshiba's donation is not unusual. Many companies, for example Britain's Rolls-Royce, have contributed to research at the University of Cambridge. What is unusual is that, in return for its large donation, Hitachi will gain control of about a quarter of the new building with its own private entrance.

Hitachi will set up joint research projects with University of Cambridge researchers. The first couple of Hitachi researchers will arrive in May and will collaborate with Ahmed and one of his students on the computer simulation of future microelectronic devices. When the new building opens in December, Hitachi will increase its laboratory staff to about ten, including several British researchers, and the company will pump in annual research funds of about $¥ 200-250$ million (about $£ 1$ million), says Hitachi vice president Hiroshi Watanabe. The researc centres in Ireland and the United States will be of similar size. And within about ten years, Watanabe hopes to expand the total number of researchers in Europe and the United States to about 200, dispersed among small laboratories of 10-20 researchers, with most of the staff recruited locally.

Hitachi is just one of several Japanese companies that have recently established research centres linked to universities in the West. Other examples include NEC Corporation, which will open a laboratory in Princeton, New Jersey next month that will carry out joint research on information technology, such as automatic translation machines, with Princeton University. Kobe Steel Ltd opened a polymer composites research laboratory at the University of Surrey in the United Kingdom last October. And Hitachi Chemical will use two-thirds of the space in a new biotechnology laboratory of the University of California in exchange for a $\$ 12$ million donation.

Many Japanese companies have for several years been making donations to leading US universities, for example through the endowment of university chairs. But the move to establish joint research centres is a new phenomenon and there are fears in the West that it is an attempt by Japanese companies to pick the brains of the Western world.

Ahmed, however, sees the collaboration in quite a different light. Japan leads the world in much of the research and development of microelectronics. As well as Hitachi gaining access to the University of Cambridge, Ahmed's student will spend six months in Hitachi's Central Research Laboratory in the outskirts of Tokyo which is equipped with one of the finest clean rooms in the world.

Hitachi's local subsidiary will retain patent rights to all joint research carried out with the University of Cambridge. But the Cavendish Laboratory will get "about 50 per cent" of patent royalties under its agreement with Hitachi, says Deakin. And both Deakin and Ahmed are confident that the university will gain both financially and academically from its collaboration with the Japanese company.

David Swinbanks

\section{Australia to seize the seas?}

\section{Sydney}

A NEW report on Australia's marine industries recommends a radical reorganization of the nation's marine science and technology capabilities and calls for Australia to claim its Exclusive Economic Zone, an area bigger than its land mass. But the federal Department of Science appears to be in no hurry to submit to cabinet the report's recommendations, which would cost A $\$ 11.7$ million to put into effect. The full report will be made public shortly.

Increasing interest by foreign governments in Australia's fishing zones, the growth in visitors to the Great Barrier Reef and the potential of off-shore oil and gas prompted the government last year to convene a committee chaired by Professor Ken McKinnon, vice-chancellor of Wollongong University.

Marine industries are at present worth more than $\mathrm{A} \$ 16,000$ million annually, of which $\mathrm{A} \$ 4,500$ million is gross export income. The federal government spends A $\$ 70$ million a year on marine research and development but there has been no growth for four years.

In line with the government's view that industry should help pay for the development of technology, the report recommends upgrading of areas such as aqua/ culture, marine biotechnology and seabed mineral assessment. "The picture which emerges is that our efforts in the marine field are unbalanced. A large proportion is concentrated on marine biology and too little in the physical sciences and technology. There are vast amounts of money to be made in marine technology fields, the incentive for industry is untapped profit", McKinnon said.

The report says that previously unharvested species of fish could be exploited in Australia's Exclusive Economic Zone and calls for a personal levy on tourists visiting the Great Barrier Reef "to help maintain the reef in its original state". The committee proposed the formation of a statutory Australian Marine Industries and Sciences Council (AMISC) with responsibiliity for policy, planning and funding. Eighteen different government departments have an interest in marine sciences, according to the report, so there is likely to be disagreement as to which should take responsibility.

Joe Baker, director of the Australian Institute of Marine Science (AIMS), welcomed the recommendations. "Overall the report brings together data that has been, until now, scattered. We recognize that there must be the incentive for industry to invest in the marine environment and we recognize that, ultimately, AIMS, together with the oceanography and fishing divisions of the Commonwealth Scientific and Industrial Research Organisation and some components of the Bureau of Meteorology and the Antarctic Division will have to be incorporated into a larger structure."

Tanla Ewing 